\title{
Achieving Consensus on Continuing Professional Development Priorities for Registered Nurses in Rural and Remote India through Nominal Group Technique
}

\author{
Annetta Smith ${ }^{1}$, Leah Macaden', Maryann Washington², Prem K. Mony², Vinay John ${ }^{3}$, \\ Fr Santosh Dias 4 \\ ${ }^{1}$ Department of Nursing, Centre for Health Science, University of the Highlands \& Islands, Inverness, UK \\ ${ }^{2}$ Division of Epidemiology and Population Health, St John's Research Institute, Bangalore, India \\ ${ }^{3}$ Emmanuel Hospital Association (EHA), Chhatarpur, India \\ ${ }^{4}$ President, Catholic Health Association India (CHAI), Karnataka, India \\ Email: *annetta.smith@uhi.ac.uk
}

How to cite this paper: Smith, A., Macaden, L., Washington, M., Mony, P.K., John, V. and Dias, F.S. (2018) Achieving Consensus on Continuing Professional Development Priorities for Registered Nurses in Rural and Remote India through Nominal Group Technique. Open Journal of Nursing, 8, 848-859.

https://doi.org/10.4236/ojn.2018.811064

Received: September 26, 2018

Accepted: November 26, 2018

Published: November 29, 2018

Copyright $\odot 2018$ by authors and Scientific Research Publishing Inc. This work is licensed under the Creative Commons Attribution International License (CC BY 4.0).

http://creativecommons.org/licenses/by/4.0/

\begin{abstract}
Background: Nurses can often be key frontline healthcare professionals working in remote and rural settings due to resource constraints including an acute shortage of medical practitioners. The provision of regular and appropriate Continuing Professional Development (CPD) to support nurses to be able to provide effective health care therefore becomes even more significant in these settings. Engagement and "buy in" from relevant stakeholders at an organisational level is a critical step to ensure CPD provision for nurses. $\mathrm{Ob}$ jectives: The overall aim was to achieve consensus on CPD for registered nurses working in remote and rural settings among key stakeholders using the Nominal Group Technique (NGT). The objectives were to identify stakeholders' perspectives on the priorities for CPD training for registered nurses; the preferred modes of delivery for $\mathrm{CPD}$ and perceived barriers and facilitators for CPD access. Methods: NGT was used as a qualitative method with key organisational stakeholders in several iterative stages in the form of a workshop. Results: 22 senior healthcare professionals involved in medical and nursing education representing north, northeast, central India and the state of Karnataka in South India participated in the workshop. Three key findings emerged from this study: priorities of CPD; preferred modes of CPD delivery; barriers and facilitators to $\mathrm{CPD}$ access. Conclusion: Engagement with key stakeholders to identify CPD priorities can help facilitate strategic planning and provision of relevant and accessible CPD programmes for nurses working within remote and rural health care contexts in India.
\end{abstract}




\section{Keywords}

Continuing Professional Development, Nurses, India, Remote and Rural, Nominal Group Technique

\section{Introduction}

Alterations in global disease patterns and the evolving nature of healthcare delivery reinforce the need for nurses and other Health Care Professionals (HCPs) to respond to contextual healthcare needs. Effective CPD is required for nurses to gain up to date knowledge and skills to meet a wide range of health care needs of the population they serve [1]. When populations are large and diverse, the need for a strategic approach to planning CPD provision becomes even more essential. India accounts for $21 \%$ of the global disease burden [2] and as nurses constitute a major portion (38\%) of human resources within India's healthcare system [3] it becomes even more imperative that that they have access to regular CPD provision. The Indian Nursing Council now mandates evidence of CPD participation (a minimum of 30 credit hours per year) towards the renewal of nurses' professional registration every five years [4] similar to professional regulators in developed countries. However, making CPD mandatory without relevant resources or mechanisms to deliver and monitor CPD provision does not guarantee access to CPD or serve its intended purposes [5].

While there is no universally agreed definition for CPD, it is generally accepted that its purpose is to help nurses maintain an updated skill set in order to maintain fitness to practise, and to respond to the changing technologies and demands of healthcare delivery [6]. Nurses engage with CPD for organisational, professional and personal reasons [7] with reciprocal benefits for providers and recipients of care [8]. Participation in CPD programmes has been shown to positively influence patient safety and quality of patient care [9] [10] increase job satisfaction [11] lower stress levels and facilitate stronger organisational commitment [12] and staff morale [13]. Significantly, nurses working in rural and remote settings in India identified CPD training as an opportunity to enhance their opportunities for socialisation, signifying the potential for professional isolation practitioners can often encounter in these settings [14].

Several factors that contribute to nurses' lack of engagement with CPD programmes have remained consistent across the literature over the last 20 years regardless of the country and geographical location [15]. These include personal barriers, including family commitments, cost, distance to venue [15] [16] and organisational barriers, comprising staff shortages, lack of relevant CPD and employer support [15] [17]. Importantly, access to CPD for nurses in rural areas may be further limited due to lack of opportunities and availability of resources [16] [18]. These findings resonate with a recent scoping study on CPD needs of registered nurses working in rural and remote settings in India [14]. 
Due to its pluralistic nature, health care provision in India is increasingly asymmetric and disproportionate with the private sector being the largest provider [19]. Recruiting qualified health care professionals to rural and remote settings is a significant challenge and people living in rural parts of India often lack health care provision from qualified providers [20] [21]. However, nurse education in India has also had to contend with neglect for several decades due to the disproportionate focus and attention on medical education, and the political leverage of the medical community [19]. Within the public sector, lack of autonomy and disempowerment of nurses and geographical imbalance negatively impact on the provision of high quality nursing education [22]. A significant nursing shortage in India [23] predominantly due to nurse migration adds further to these complexities [24]. Yet, nurses have been identified as crucial members of the Indian healthcare workforce with an expectation that they assume key roles within the national plans for universal health coverage [25]. Furthermore, it is widely accepted that health workers in sufficient numbers in the right places, adequately trained, motivated and supported are the backbone of an effective, equitable, and efficient health care system [26]. Strategic health priorities must therefore include accredited education that is inclusive of CPD that aims to support delivery of effective health care interventions [2]. This is particularly vital for nurses and other HCPs who work in remote settings with limited resources and where opportunities for CPD are scarce [23].

Engagement with CPD should be viewed as a shared professional responsibility both by organisations and health care professionals because of its mutual benefit resulting in improved and safe nursing care of patients [27] [28]. More importantly, a proactive leadership and organizational culture that facilitates learning are critical to support nurses' professional development requirements [17]. Healthcare organizations are expected to provide well-resourced and appropriate infrastructure for nurses' continuing education and development [19] [29] [30]. Evidence suggests that nurses work more effectively with improved patient care outcomes in organizations that prioritise CPD with access to learning opportunities and resource, for example, time, paid study leave and flexible rostering [31] [32]. Therefore, there is a requirement for relevant stakeholders at an organizational level to be involved in both planning and provision of CPD for nurses working within their organizations [33]. Both within India and further afield, there is an increasing recognition that developing and co-producing CPD programmes for all HCPs including nurses with relevant stakeholders can help address contextual healthcare needs more effectively [10] [34].

This research was part of a larger two-phase study. Phase one involved a questionnaire survey with registered nurses working in two large, not-for-profit health care organisations in remote and rural settings in India [14]. Nurses identified CPD priorities, their preferred modes of CPD delivery, barriers and facilitators to CPD [14]. Phase two of the study aimed to achieve consensus with key stakeholders (academics and practitioners) in these domains of CPD for regis- 
tered nurses working in rural and remote settings in India. This paper reports on phase two of the research with data gathered from key stakeholders using NGT

[35]. NGT is a form of qualitative inquiry that can be used when no definitive empirical data is available to answer important questions [35]. It is one of the most commonly used formal consensus development methods [36] [37], which employ face-to-face structured meetings. The collaborative nature of NGT facilitates participants' ownership of the process increasing the likelihood of the change required in clinical practice and policy [38]. This approach was selected, as it was important to facilitate a process of consensus and validation among key stakeholders who were responsible and strategically placed for both planning and provision of CPD [39]. An advantage of NGT is that each participant is given equal opportunity to generate and present suggestions [40] [41] diminishing the risk of individual bias [40].

\section{Methods}

Aim: To achieve consensus on CPD for registered nurses working in remote and rural settings among key stakeholders using NGT.

Objectives: To achieve stakeholder consensus on:

1) The priorities for CPD training for registered nurses within the remote and rural contexts.

2) Preferred modes for CPD delivery for registered nurses in these contexts.

3) Perceived barriers and facilitators with access to CPD for registered nurses in these contexts

Participants: 22 healthcare professionals involved in medical and nursing education.

\section{Data collection}

NGT was used as a method to achieve consensus from participants on the above objectives in July 2015 in Bangalore, India. NGT was conducted in several iterative stages by the lead facilitator from the research team over one day. Data analysis from the consensus workshop [42] and was facilitated by the researchers (AS, LM, MAW, PM). We adapted seven stages of NGT [43] as illustrated in Figure 1. In compliance with stage 1 of the NGT process, participants were given an overview of the overall project's aim and objectives [14] and the aim and objectives of the Stakeholders' workshop using NGT. The preliminary findings from phase one (Questionnaire survey on CPD needs assessment) with registered nurses in remote and rural settings were presented (Stage 2 of NGT).

In stage 3, all the participants were invited to independently generate written responses to the following question. 'What are the key education priorities for CPD for nurses working in remote hospitals?' They were then asked to share their ideas with the group (Stage 4) and these ideas were recorded on flip charts to allow all group members to consider the group's contribution [43] which was used as raw data. Similar ideas were then grouped to develop relevant themes [41], which were then verified and agreed by all participants. The discussion 


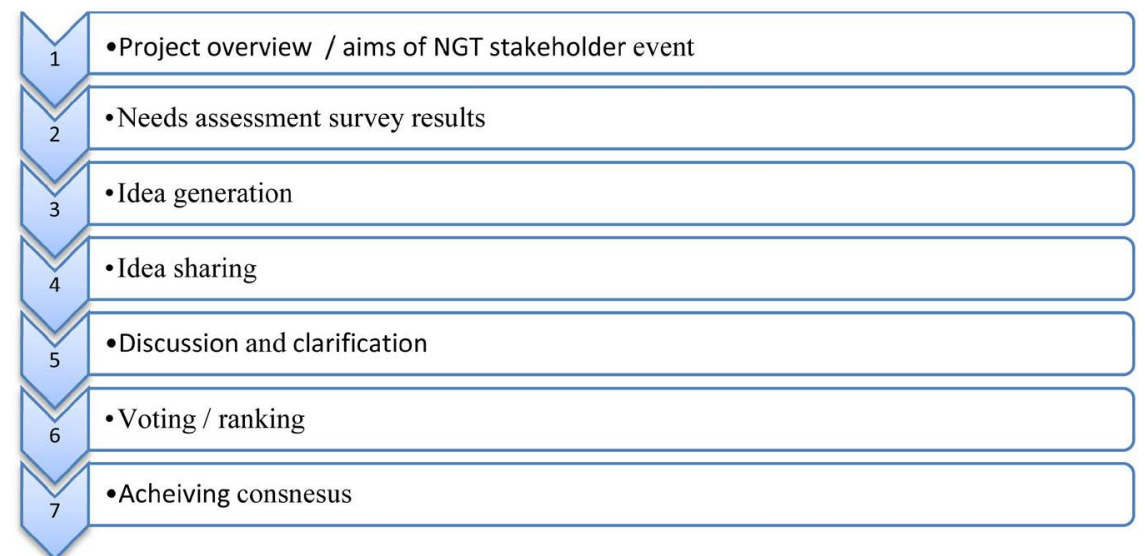

Figure 1. Stages of NGT used with the stakeholders.

and clarification during Stage 5 provided participants with the opportunity to refine ideas, ensuring that everyone was confident with the meaning and intentions of ideas generated and closely related ideas were further combined with participants' inputs. Participants were then asked to independently rank ideas under each of the three themes from 1 to 10 with 1 being identified as the highest priority. The results of the ranking were then discussed by the group and group consensus for key CPD priorities was achieved. The NGT process described above was then followed to achieve consensus for the two following questions.

- What are the preferred delivery modes for CPD courses?

- What are the key barriers and facilitators to development and delivery of $\mathrm{CPD}$ for nurses in remote areas?

\section{Ethics approval}

Institution Ethics Committee approval: Ethics approval for the project was obtained from the Institutional Ethics Committee [IEC] of St John's Medical College [IEC Ref No. 156/2015 dated 22 June 2015], Bangalore which is recognised by the Drug Controller General of India [DCGI], Government of India.

\section{Results}

Sixteen out of the 22 participants had first-hand experience of working and/or teaching in rural and remote contexts within India. The stakeholder event was attended by three CEOs representing two health care organisations that are largely operational in remote and rural parts of India where the CPD needs assessment was conducted (Phase 1). Other participants included Nurse Directors (2), Senior Nurse Academics (10), Senior Medical Academics (3), Medical Educators (2) and Nurse Educators (2) representing north, northeast, central India and the state of Karnataka in South India.

The analysis of the results from the consensus event is presented as follows.

\section{CPD priorities}

Table 1 presents CPD priorities in their ranking order as identified by the 
participants. The highest ranked topic areas for CPD included broader generic skills required to deliver safe and informed care, with the more disease-focused CPD provision ranked lower.

\section{Preferred modes for CPD delivery}

A number of teaching and learning methods were identified that included pedagogical approaches to teaching and learning (Table 2). Whilst a range of delivery modes were identified, the most favoured were those that utilised technology.

\section{Barriers and facilitators for access to CPD}

Table 3 presents the ranked barriers and facilitators to CPD provision. Three interconnected themes emerged from the data (personal, professional and organisational) which were considered to either restrict or enhance CPD access for nurses.

Table 1. Ranked priorities.

\begin{tabular}{cc}
\hline Ranking & Topic areas \\
\hline 1 & Communication and management \\
2 & Ethics, professional values and legal issues \\
3 & Quality and safety \\
4 & Evidence Based Practice (EBP) and critical thinking \\
5 & Information technology (IT) \\
& Clinical skills and medical devices \\
6 & Health and welfare policy awareness \\
7 & Emergency and disaster management \\
& Mental health \\
8 & Infection control \\
& Stress management \\
10 & Lifespan specific care \\
& Community based rehabilitation \\
& Non communicable diseases
\end{tabular}

Table 2. Ranked preferences for pedagogical methods of CPD delivery.

\begin{tabular}{cccc}
\hline $\begin{array}{c}\text { Pedagogical methods } \\
\text { Skill labs \& simulation }\end{array}$ & Ranking & Modes of Delivery & Ranking \\
\hline $\begin{array}{c}\text { Case based / Problem Based Learning (PBL) } \\
\text { Cascade learning e.g. "Training the Trainers" }\end{array}$ & 2 & E modules & 1 \\
Competency led education & 4 & Mobile applications (APPS) & 3 \\
Peer mentoring & 5 & Face to Face (FtF) teaching & 5 \\
Networking/ exchange opportunities & 6 & Blended learning approaches & 6 \\
Pre-course learning materials & 7 & Paper based learning materials & 7
\end{tabular}


Table 3. Ranked barriers and facilitators for access to CPD.

\begin{tabular}{|c|c|c|c|c|}
\hline Themes & Barriers & Ranking & Facilitators & Ranking \\
\hline \multirow{3}{*}{ Personal } & Poor motivation & 1 & $\begin{array}{l}\text { Incentivisation e.g. } \\
\text { promotion/salary }\end{array}$ & 1 \\
\hline & Family responsibilities & 2 & High motivation & 2 \\
\hline & Finance & 3 & Language accessible & 3 \\
\hline \multirow{4}{*}{ Professional } & $\begin{array}{l}\text { Lack of professional } \\
\text { recognition }\end{array}$ & 1 & $\begin{array}{l}\text { Professional/academic } \\
\text { accreditation }\end{array}$ & 1 \\
\hline & Lack of career progression & 2 & $\begin{array}{l}\text { Collaboration between } \\
\text { CPD providers and } \\
\text { professional bodies }\end{array}$ & 2 \\
\hline & Lack of accreditation & 3 & Quality CPD provision & 3 \\
\hline & Limited or irrelevant CPD & 4 & & \\
\hline \multirow{5}{*}{ Organisational } & $\begin{array}{l}\text { Unsupportive management } \\
\text { and work culture }\end{array}$ & 1 & $\begin{array}{l}\text { Organisational recognition } \\
\text { and strategic vision }\end{array}$ & 1 \\
\hline & Sustainability & 2 & $\begin{array}{l}\text { Maximise use of existing } \\
\text { resources and structures }\end{array}$ & 2 \\
\hline & No designated study time & 3 & Finance & 3 \\
\hline & Staffing restrictions & 4 & Accessibility & 4 \\
\hline & Lack of finance & 5 & & \\
\hline
\end{tabular}

${ }^{*}$ For example, Indian Nursing Council (INC), Trained Nurses' Association of India (TNAI) and the State Nursing Council (SNC).

\section{Discussion}

The overall purpose of this study was to achieve consensus with key stakeholders on $\mathrm{CPD}$ requirements of registered nurses working across geographically diverse regions in remote and rural India. Findings from this study further extend our understanding of stakeholder perspectives on the challenges and solutions to $\mathrm{CPD}$ provision within that context. Capturing this perspective is important to influence the strategic planning and provision of relevant CPD for both personal and professional development of nurses working in these settings. Key findings from this phase of the study included: CPD priorities; mode/s for CPD delivery and barriers and facilitators for access to CPD.

CPD priorities included broader and generic competencies required to deliver safe and informed care, with more disease-focused education ranked lower down. For example, communication and management achieved the highest ranking and there is evidence to support a correlation between high quality management skills and outcomes such as higher quality care, better productivity and fewer patient complaints [44]. Yet, nurses often lacked formal training for their management role [26] [45]. It was interesting to note the paradox with CPD priorities identified between stakeholders and nurses in that CPD for Non Communicable Diseases (NCDs) was ranked as the lowest priority by stakeholders whilst, nurses identified NCDs as one of the priority areas for knowledge 
development [14], perhaps reflective of the increasing burden of NCDs in India [2].

In relation to modes of CPD delivery, consensus from both the stakeholders and findings from the survey with registered nurses [14] confirmed preference towards skills based training/simulations to deliver CPD. Other studies also report that simulation is a superior method to train across a broad range of clinical skills [46]. Stakeholders also ranked their preference for CPD delivery using a range of technologies that would increase the potential to facilitate wider access to CPD [47]. For example, the increasing use of computer-based models for simulation could provide the opportunity to both deliver skills training and improve accessibility particularly for nurses working in remote settings.

Stakeholders identified personal, professional and organisational barriers to CPD access and these were largely reflective of the existing and longstanding global evidence base in this area [14] [15] [17]. However, the challenges of remote and rural working can further heighten these barriers [50] and pose a special challenge because of cost and staffing issues [48]. Stakeholders identified a range of facilitators to support nurses' engagement with $\mathrm{CPD}$ and ranked recognition of CPD (for example by award of accreditation, promotion or increased remuneration) as the most significant. This is an important finding in the context of this study as previous research demonstrates that factors such as income and workload were significant predictors of practitioner retention in rural areas [49]. However, on the contrary, evidence suggests that nurses in India lack clear career pathways and mechanisms for promotion [50] in most health care organizations.

In this study, NGT provided a structured forum for key stakeholders to come together face-to-face, and who because of work commitments and distance would not normally have this opportunity. Consensus methods, particularly in practice-based disciplines such as nursing can integrate evidence with pragmatic considerations of systems, professional values and consumer needs [39].

The commitment to CPD is a shared relationship between individual nurses and organizations integral to the nursing profession [51]. Success in creating and sustaining an effective healthcare workforce in India to achieve national health goals will require sound policies with creativity and commitment towards implementation [26]. Within India's remote and rural context, the vision to build capacity and capability among nurses working both in private and public sectors through relevant and accessible CPD programmes needs to be pursued through wider collaboration with relevant stakeholders. Consideration of multiple sources of evidence such as findings from both the NGT stakeholder event and survey [14] will inform planning for relevant and accessible CPD for nurses in India working in remote and rural contexts but also has the potential for wider application. This is important because it is widely recognized that meeting the health care needs of rural populations will become increasingly more reliant on nurses who possess the knowledge and skillset that meet the demands and challenges of managing and delivering care within those contexts [27]. 


\section{Limitations}

There were 22 participants in total and the stakeholders (17 out of 22) predominantly represented the southern States of Tamilnadu, Karnataka with a lack of representation from the rest of India. A possible disadvantage of using NGT as we have described is that there may have been some conformity by participants, for example opinions may not have always converged during the ranking process.

\section{Authors' Contributions}

AS, LM, MW, PM developed the methodology; VJ, SD Organising and supporting the NGT consensus event; AS, LM, MW, PM, organisation and preparation of the manuscript $\mathrm{VJ}, \mathrm{SD}$, manuscript review.

\section{Acknowledgements}

The authors are very grateful to all the participants, coordinators and support from the Management of CHAI \& EHA, India; the administrative support for the project from Mrs. Sunitha Pinto \& Ms. Sumi Anu Niranjan at SJRI, Bangalore, India.

\section{Supported}

This project was supported by the Tropical Health \& Education Trust (THET) as part of the Health Partnership Scheme, which is funded by the UK Department for International Development (DFID).

\section{Conflicts of Interest}

The authors declare no conflict of interest.

\section{References}

[1] Manley, K., Martin, A., Jackson, C. and Wright, T. (2018) A Realist Synthesis of Effective Continuing Professional Development (CPD): A Case Study of Healthcare Practitioners' CPD. Nurse Education Today, 69, 134-141.

https://doi.org/10.1016/j.nedt.2018.07.010

[2] WHO (2018) Country Cooperation Strategy http://www.who.int/country-cooperation/what-who-does/strategies-and-briefs/en/

[3] Gill, R. (2011) Nursing Shortage in India with Special Reference to International Migration of Nurses. Social Medicine, 6, 52-59.

[4] Delhi Nursing Council (2016) Registration Renewal Procedure. http://delhinursingcouncil.com/Registration-Renewal-Procedure.asp

[5] James, A. and Francis, K. (2011) Mandatory Continuing Professional Education: What Is the Prognosis? Collegian, 18, 131-136. https://doi.org/10.1016/j.colegn.2011.03.001

[6] RCN Factsheet: Continuing Professional Development (CPD) for Nurses Working in the United Kingdom (UK) (2014).

https://matrix.rcn.org.uk/_data/assets/pdf_file/0006/583260/16.14_RCN_Factsheet 
Continuing_Professional_Development_for_nurses_working_in_the_UK.pdf

[7] Flores Peña, Y. and Alonso Castillo, M. (2006) Factors Influencing Nursing Staff Members' Participation in Continuing Education. Revista Latino-Americana de Enfermagem, 14, 309-315. https://doi.org/10.1590/S0104-11692006000300002

[8] Billett, S. (2010) The Perils of Confusing Lifelong Learning with Lifelong Education. International Journal of Lifelong Education, 29, 401-413. https://doi.org/10.1080/02601370.2010.488803

[9] Schostaka, J., Davisb, M. and Hansonc, J.S. (2010) The Effectiveness of Continuing Professional Development. A report prepared on behalf of College of Emergency Medicine, Federation of Royal Colleges of Physicians and Manchester Metropolitan University. General Medical Council UK.

[10] Srinivas, D.K. and Adkoli, B.V. (2009) Faculty Development in Medical Education in India: The Need of the Day. Al Ameen Journal of Medical Sciences, 2, 6-13.

[11] Skår, R. (2010) How Nurses Experience Their Work as a Learning Environment. Vocations and Learning, 3, 1-18. https://doi.org/10.1007/s12186-009-9026-5

[12] Chien, C.C., Chou, H.K. and Hung, S.T. (2008) A Conceptual Model of Nurses' Goal Orientation, Service Behavior, and Service Performance. Nursing Economics, 26, 374-383.

[13] Shields, M.A. and Ward, M. (2001) Improving Nurse Retention in the National Health Service in England: The Impact of Job Satisfaction on Intentions to Quit. Journal of Health Economics, 20, 677-701. https://doi.org/10.1016/S0167-6296(01)00092-3

[14] Macaden, L., Washington, M., Smith, A., Thooya, V., Selvam, S.P., George, N. and Mony, P.K. (2017) Continuing Professional Development: Needs, Facilitators and Barriers of Registered Nurses in India in Rural and Remote Settings: Findings from a Cross Sectional Survey. Open Journal of Nursing, 7, 930-948.

https://doi.org/10.4236/ojn.2017.78069

[15] Ross, K., Barr, J., and Stevens, J. (2013) Mandatory Continuing Professional Development Requirements: What Does This Mean for Australian Nurses. BMC Nursing, 12, 9. https://doi.org/10.1186/1472-6955-12-9

[16] Penz, K., D’Arcy, C., Stewart, N., Kosteniuk, J., Morgan, D. and Smith, B. (2007) Barriers to Participation in Continuing Education Activities among Rural and Remote Nurses. The Journal of Continuing Education in Nursing, 38, 58-66. https://doi.org/10.3928/00220124-20070301-03

[17] Coventry, T.H., Maslin-Prothero, S.E. and Smith, G. (2015) Organizational Impact of Nurse Supply and Workload on Nurses Continuing Professional Development Opportunities: An Integrative Review. Journal of Advanced Nursing, 71, 2715-2727. https://doi.org/10.1111/jan.12724

[18] Humphreys, J., Wakerman, J., Pashen, D. and Buykx, P. (2017) Retention Strategies and Incentives for Health Workers in Rural and Remote Areas: What Works?

[19] Rao, M., Rao, K., Shiva Kumar, A., Chatterjee, M. and Sundararaman, T. (2011) Human Resources for Health in India. The Lancet, 377, 587-598. https://doi.org/10.1016/S0140-6736(10)61888-0

[20] Banerjee, A., Deaton, A. and Duflo, E. (2004) Wealth, Health, and Health Services in Rural Rajasthan. American Economic Review, 94, 326-330. https://doi.org/10.1257/0002828041301902

[21] Das, J. and Hammer, J. (2007) Location, Location, Location: Residence, Wealth, and the Quality of Medical Care in Delhi, India. Health Affairs, 26, w338-w351. 
https://doi.org/10.1377/hlthaff.26.3.w338

[22] Evans, C., Razia, R. and Cook, E. (2013) Building Nurse Education Capacity in India: Insights from a Faculty Development Programme in Andhra Pradesh. BMC Nursing, 12, 8. https://doi.org/10.1186/1472-6955-12-8

[23] Tiwari, R.R., Sharma, K. and Zodpey, S.P. (2013) Situational Analysis of Nursing Education and Work Force in India. Nursing Outlook, 61, 129-136. https://doi.org/10.1016/j.outlook.2012.07.012

[24] Hawkes, M., Kolenko, M., Shockness, M. and Diwaker, K. (2009) Nursing Brain Drain from India. Human Resources for Health, 7, 5. https://doi.org/10.1186/1478-4491-7-5

[25] Bhaumik, S. (2013) Can India End the Corruption in Nurses' Training? BMJ, 347, f6881. https://doi.org/10.1136/bmj.f6881

[26] Raha, S., Berman, P. and Bhatnagar, A. (2009) Some Priority Challenges of the Nursing Sector in India. https://openknowledge.worldbank.org/handle/10986/12820

[27] Hughes, E. (2005) Nurses' Perceptions of Continuing Professional Development. Nursing Standard, 19, 41-49. https://doi.org/10.7748/ns2005.07.19.43.41.c3904

[28] Hegney, D., Tuckett, A., Parker, D. and Robert, E. (2010) Access to and Support for Continuing Professional Education amongst Queensland Nurses: 2004 and 2007. Nurse Education Today, 30, 142-149. https://doi.org/10.1016/j.nedt.2009.06.015

[29] Glasper, A. (2018) Problems Affecting the Continuing Professional Development of Nurses. British Journal of Nursing, 27, 714-715. https://doi.org/10.12968/bjon.2018.27.12.714

[30] Purdy, N., Spence Laschinger, H.K., Finegan, J., Kerr, M. and Olivera, F. (2010) Effects of Work Environments on Nurse and Patient Outcomes. Journal of Nursing Management, 18, 901-913. https://doi.org/10.1111/j.1365-2834.2010.01172.x

[31] Johnson, A., Hong, H., Groth, M. and Parker, S.K. (2011) Learning and Development: Promoting Nurses' Performance and Work Attitudes. Journal of Advanced Nursing, 67, 609-620. https://doi.org/10.1111/j.1365-2648.2010.05487.x

[32] Katsikitis, M., McAllister, M., Sharman, R., Raith, L., Faithfull-Byrne, A. and Priaulx, R. (2013) Continuing Professional Development in Nursing in Australia: Current Awareness, Practice and Future Directions. Contemporary Nurse, 45, 33-45. https://doi.org/10.5172/conu.2013.45.1.33

[33] Brekelmans, G., Poell, R.F. and van Wijk, K. (2013) Factors Influencing Continuing Professional Development: A Delphi Study among Nursing Experts. European Journal of Training and Development, 37, 313-325. https://doi.org/10.1108/03090591311312769

[34] World Health Organization (2010) Framework for Action on Interprofessional Education and Collaborative Practice (No. WHO/HRH/HPN/10.3). World Health Organization, Geneva. http://www.who.int/hrh/resources/framework_action/en/

[35] Shortt, S.E.D., Guillemette, J.M., Duncan, A.M. and Kirby, F. (2010) Defining Quality Criteria for Online Continuing Medical Education Modules Using Modified Nominal Group Technique. Journal of Continuing Education in the Health Professions, 30, 246-250.

[36] Van De Ven, A.H. and Delbecq, A.L. (1974) The Effectiveness of Nominal, Delphi, and Interacting Group Decision Making Processes. Academy of Management Journal, 17, 605-621. https://doi.org/10.5465/255641

[37] Gallagher, M., Hares, T., Spencer, J., Bradshaw, C. and Webb, I. (1993) The Nominal Group Technique: A Research Tool for General Practice? Family Practice, 10, 
76-81. https://doi.org/10.1093/fampra/10.1.76

[38] Vella, K., Goldfrad, C., Rowan, K., Bion, J. and Black, N. (2000) Use of Consensus Development to Establish National Research Priorities in Critical Care. BMJ, 320, 976-980. https://doi.org/10.1136/bmj.320.7240.976

[39] Halcomb, E.J., Davidson, P.M., Salamonson, Y., Ollerton, R. and Griffiths, R. (2008) Nurses in Australian General Practice: Implications for Chronic Disease Management. Journal of Clinical Nursing, 17, 6-15. https://doi.org/10.1111/j.1365-2702.2007.02141.x

[40] Murphy, M.K. (1998) Consensus Development Methods, and Their Use in Clinical Guideline Development. Health Technology Assessment, 2, 1-88.

[41] Harvey, N. and Holmes, C.A. (2012) Nominal Group Technique: An Effective Method for Obtaining Group Consensus. International Journal of Nursing Practice, 18, 188-194. https://doi.org/10.1111/j.1440-172X.2012.02017.x

[42] James, D.J. and Warren-Forward, H.M. (2015) Development of Consensus Statements for Pregnancy Screening in Diagnostic Nuclear Medicine: A Delphi Study. Journal of Nuclear Medicine Technology, 43, 74-79.

[43] McCawley, P.F. (2009) Methods for Conducting an Educational Needs Assessment. University of Idaho, Moscow, ID, 23.

[44] King's Fund (2011) The Future of Leadership and Management in the NHS. London.

https://www.kingsfund.org.uk/sites/default/files/future-of-leadership-and-manage ment-nhs-may-2011-kings-fund.pdf

[45] Baker, S., Marshburn, D.M., Crickmore, K.D., Rose, S.B., Dutton, K. and Hudson, P.C. (2012) What Do You Do? Perceptions of Nurse Manager Responsibilities. Nursing Management, 43, 24-29. https://doi.org/10.1097/01.NUMA.0000422890.99334.21

[46] Cook, D.A., Brydges, R., Hamstra, S.J., Zendejas, B., Szostek, J.H., Wang, A.T. and Hatala, R. (2012) Comparative Effectiveness of Technology-Enhanced Simulation versus Other Instructional Methods: A Systematic Review and Meta-Analysis. Simulation in Healthcare, 7, 308-320. https://doi.org/10.1097/SIH.0b013e3182614f95

[47] Berndt, A., Murray, C.M., Kennedy, K., Stanley, M.J. and Gilbert-Hunt, S. (2017) Effectiveness of Distance Learning Strategies for Continuing Professional Development (CPD) for Rural Allied Health Practitioners: A Systematic Review. BMC Medical Education, 17, 117. https://doi.org/10.1186/s12909-017-0949-5

[48] Schweitzer, D.J. and Krassa, T.J. (2010) Deterrents to Nurses' Participation in Continuing Professional Development: An Integrative Literature Review. The Journal of Continuing Education in Nursing, 41, 441-447. https://doi.org/10.3928/00220124-20100601-05

[49] Rabinowitz, H.K. (1997) Demographic, Educational and Economic Factors Related to Recruitment and Retention of Physicians in Rural Areas. Population Health Matters (Formerly Health Policy Newsletter), 10, Article 3.

[50] Timmons, S., Evans, C. and Nair, S. (2016) The Development of the Nursing Profession in a Globalised Context: A Qualitative Case Study in Kerala, India. Social Science \& Medicine, 166, 41-48. https://doi.org/10.1016/j.socscimed.2016.08.012

[51] Gallagher, L. (2007) Continuing Education in Nursing: A Concept Analysis. Nurse Education Today, 27, 466-473. https://doi.org/10.1016/j.nedt.2006.08.007 